\title{
Ear Quality in Three Sweet Corn Populations Selected for Resistance to Common Rust
}

\author{
Bruce G. Abedon ${ }^{1}$ and William F. Tracy ${ }^{2}$ \\ Department of Agronomy, University of Wisconsin-Madison, Madison, WI 53706
}

\begin{abstract}
AdDitional INDEX WORDS. Zea mays, maize, adult plant resistance, plant pathology
Abstract. Research was conducted to evaluate correlated effects of full-sib phenotypic recurrent selection for resistance to common rust (Puccinia sorghi Schw.) on ear quality traits in three sugary1 (su1) sweet corn (Zea mays L.) populations: Minn11, Minn14, and NECDR. Cycles 0, 1, 2, and 3 of each population were evaluated in both rust infested and nonrust infested environments. Generally, selection for rust resistance resulted in significant, but minor, decreases in ear and kernel size. Changes in specific traits varied with population. The nonsignificant cycle $\times$ environment interaction indicates similar responses occurred in all environments evaluated. Based on these results, selection for ear quality traits need not accompany selection for resistance to common rust if maintenance of ear quality is desired.
\end{abstract}

Common rust (Puccinia sorghi) is a major pathogen of sweet corn (Zea mays) in the north central United States. Infection results in reduced ear and kernel size, poor tip fill, and decreased uniformity (Groth et al., 1983; Randle et al., 1984b). Fungicidal control is available but it is expensive and timing of application is problematic (Pataky and Headrick, 1989). Genetic resistance is a cost-effective alternative control strategy.

Adult plant resistance to common rust develops during ontogeny, resulting in upper leaves with increased resistance relative to lower, seedling leaves (Hooker, 1969). Because resistance is quantitatively inherited with high heritability (Hooker, 1969; Kim and Brewbaker, 1977; Randle et al., 1984a), recurrent selection is a useful breeding method for improvement. Three cycles of full-sib phenotypic recurrent selection for resistance to common rust in three sweet corn populations, Minn11, Minn14, and NECDR, resulted in decreased mean rust infection in each population (Abedon and Tracy, 1998). Percent leaf area infected decreased 5.6\%/cycle in Minn11, 3.4\%/cycle in Minn14, and $4.6 \% / c y c l e$ in NECDR when measured $21 \mathrm{~d}$ after pollination under artificial inoculation conditions.

Recurrent selection for one trait may result in a correlated response in other agronomically important traits due to pleiotropy, linkage, and random genetic drift. Improved ear quality resulting from increased resistance to common rust might be confounded by undesirable, correlated responses in ear quality traits that accompany selection for resistance. Knowledge of such changes will facilitate choice of improved selection procedures that maximize gain while minimizing undesirable changes. Previous reports on the effects of selection for resistance to common rust on ear quality traits and yield components are limited. Our objective was to evaluate correlated effects of full-sib phenotypic recurrent selection for resistance to common rust on ear quality traits in three sugaryl (sul) sweet corn populations: Minn11, Minn14, and NECDR.

Received for publication 13 Apr. 1998. Accepted for publication 28 June 1999 Research supported by Hatch Funds allocated to the Wisconsin Agricultural Experiment Station; the College of Agricultural and Life Sciences, and the Graduate School, University of Wisconsin-Madison; the University of Wisconsin Pioneer Hi-Bred Plant Breeding Fellowship awarded to B.G. Abedon; and The Midwest Food Processors Association. We thank J.G. Coors, I.L. Goldman, S.M. Kaeppler, and P.H. Masson for reviewing this manuscript. The cost of publishing this paper was defrayed in part by the payment of page charges. Under postal regulations, this paper therefore must be hereby marked advertisement solely to indicate this fact.

${ }^{1}$ Former graduate student.

${ }^{2}$ Professor; to whom reprint requests should be addressed.

\section{Materials and Methods}

Three sugaryl (sul) populations obtained from D. Davis of the University of Minnesota were used in this study. Minn11 and NECDR (Northeast Common Disease Resistance) are composites of multiple sweet corn and field corn inbreds. Minn14 is a composite of eight commercial sweet corn hybrids ('Miracle', 'Crookham8011', 'Del Monte 1', 'NK5658', 'Sugarloaf', 'Hallmark', 'Green Giant C23', and 'Green Giant C41') (D. Davis, personal communication).

Each population underwent three cycles of full-sib phenotypic recurrent selection for resistance to common rust at the University of Wisconsin. For the first cycle, 70 to 100 full-sib families per population were planted without replication in mid-May 1986, at the Arlington Agr. Res. Sta., Arlington, Wis. and evaluated $40 \mathrm{~d}$ after the mean tassel date of the population for percent leaf area infected by common rust. This number of days was chosen to aid selection by maximizing differences among families. The level of infection $40 \mathrm{~d}$ after the mean tassel date is greater and also is correlated with the level $21 \mathrm{~d}$ after the mean tassel date, when sweet corn is normally harvested (Abedon and Tracy, 1998). Inoculation was via natural epiphytotics because there is enough natural inoculum in southern Wisconsin to differentiate families. The selection intensity was $20 \%$. To reduce the chance of inbreeding during recombination the following year (due to self-pollination or pollination of sibs derived from the same ear), selected families within each population were divided randomly and equally into two groups (Group A and Group B). Each group consisted of a balanced bulk of remnant seed. Recombination was performed by mating a Group A plant with a Group B plant of one population, using individual plants only once as either a male or female, until all plants were pollinated. This minimized selection during recombination. A random sample of 70 to 100 full-sib families generated from the recombination step were evaluated directly for resistance to common rust for the next cycle of selection without subsequent recombination. This process was repeated for all subsequent cycles. Cycles $0,1,2$, and 3 from each population were regenerated for this study by sib-mating a minimum of 200 individuals/cycle, followed by bulking of seed within each cycle.

All field trials were conducted at the West Madison Agr. Res. Sta., Madison, on a Plano silt loam (fine-silty, mixed, mesic Typic Argiudolls). Cycles 0, 1, 2, and 3 from each population were grown in randomized complete block designs with four replications. Each population was located in a separate place in the field and evaluated as a separate experiment. Plantings were made on 
6 May 1994, 7 June 1994, and 19 May 1995 for each population. For all plantings, treatments consisted of three-row plots. Thirty kernels per row were planted followed by thinning to 15 plants/row ( $3.5 \mathrm{~m}$ long on $0.76 \mathrm{~m}$ centers) at midwhorl stage to achieve a final density of 44,500 plants/ha. Border rows of a sul hybrid ('Jubilee') were grown to minimize contamination by non-sul pollen.

Correlated responses in several ear traits were determined in environments with and without infestation by common rust. In the June 1994 experiment, two spreader plants of the sweet corn cultivar 'Jubilee' were planted in a hill at the end of each row and inoculated with common rust at midwhorl stage (mid-July). Three milliliters of a uredospore suspension $(5 \mathrm{mg}$ of uredospores in $400 \mathrm{~mL}$ deionized $\mathrm{H}_{2} \mathrm{O}$ with five drops of Tween 20 added to prevent clumping) were injected into the whorl using a repipetter. The source of inoculum was a field-derived mixture of uredospores collected the previous year and then increased in the greenhouse on seedlings of 'Jubilee'. Infection of experimental rows in the June planting occurred due to the spread of inoculum from spreader plants and also naturally. Early plantings normally escape natural inoculation. Artificial inoculation was not performed in May plantings to determine effects of selection in environments with minimal infection. Percent leaf area infected in each planting was determined visually at eating stage, about 21 $\mathrm{d}$ after silk emergence and reported previously (Abedon and Tracy, 1998).

At kernel maturity, 40 days after pollination, the uppermost ear of each of 10 competitive plants in the center row of each three-row plot was harvested and dried under forced-air conditions $\left(60^{\circ} \mathrm{C}\right)$ to constant dry weight. Data were collected on five randomly chosen ears from each plot. The other five ears were discarded. Traits evaluated included: ear length $(\mathrm{cm})$, ear width $(\mathrm{cm})$ at midpoint, cob width $(\mathrm{cm})$ at midpoint, row number, number of kernels/row, and 100 kernel weight $(\mathrm{g})$. Kernel depth $(\mathrm{cm})$, kernel width $(\mathrm{cm})$, and kernel thickness $(\mathrm{cm})$ were calculated according to the following equations: kernel depth $=($ ear width - cob width $) / 2$, kernel width $=(2 \mathrm{~B} \times$ ear width $) /(2 \times$ row number), kernel thickness= ear length/number of kernels per row.

All traits were analyzed on a sample mean basis. Analysis of variance was performed for each trait in each population. Each year and planting date combination was considered a separate environment. A single degree of freedom orthogonal contrast tested rust infested vs. nonrust infested environments (June vs. May plantings, respectively). Linear and quadratic regression models were fit to entry means across environments and replications to determine response to selection as proposed by Eberhart (1964). If the linear response was nonsignificant, the quadratic response was not tested. Cycle effects were considered fixed while year and planting date, and block, effects were considered random. The denominator of the $\mathrm{F}$ test for environments; cycles; and linear, quadratic, and residual components of cycles was the corresponding mean square for entry $\times$ environment interaction. If the entry $x$ year and planting date mean square was not

Table 1. Means and least squares estimates of indirect responses in ear traits, averaged across environments, in cycles 0 to 3 of sweet corn populations Minn11, Minn14, and NECDR selected for resistance to common rust.

\begin{tabular}{|c|c|c|c|c|c|c|c|c|}
\hline & $\begin{array}{c}\text { Ear } \\
\text { length }\end{array}$ & $\begin{array}{c}\text { Ear } \\
\text { width }\end{array}$ & $\begin{array}{c}\text { Cob } \\
\text { width }\end{array}$ & \multirow{2}{*}{$\begin{array}{c}\text { Row } \\
\text { no. }\end{array}$} & $\begin{array}{c}\text { Kernel } \\
\text { depth }\end{array}$ & $\begin{array}{l}\text { Kernel } \\
\text { width }\end{array}$ & $\begin{array}{c}\text { Kernel } \\
\text { thickness }\end{array}$ & \multirow{2}{*}{$\begin{array}{c}100 \\
\text { Kerne } \\
\text { wt }(\mathrm{g})\end{array}$} \\
\hline Cycle & & $(\mathrm{cm})$ & & & & $(\mathrm{cm})$ & & \\
\hline \multicolumn{9}{|l|}{ Minn11 } \\
\hline $\mathrm{CO}$ & 16.3 & 4.4 & 2.7 & 13.7 & 0.86 & 1.01 & 0.43 & 22.6 \\
\hline $\mathrm{C} 1$ & 17.0 & 4.4 & 2.6 & 14.1 & 0.88 & 0.99 & 0.45 & 23.1 \\
\hline $\mathrm{C} 2$ & 16.9 & 4.4 & 2.7 & 14.2 & 0.87 & 0.98 & 0.45 & 22.8 \\
\hline $\mathrm{C} 3$ & 16.5 & 4.2 & 2.6 & 13.9 & 0.80 & 0.96 & 0.45 & 22.0 \\
\hline $\operatorname{LSD}_{(0.05)}$ & NS & 0.1 & NS & NS & 0.05 & NS & NS & NS \\
\hline Linear & NS & $0.11^{*}$ & NS & NS & $0.04^{*}$ & NS & $0.01^{*}$ & NS \\
\hline Quadratic & $\mathrm{NC}^{\mathrm{z}}$ & $-0.05^{*}$ & $\mathrm{NC}$ & $\mathrm{NC}$ & $-0.02^{*}$ & $\mathrm{NC}$ & NS & $\mathrm{NC}$ \\
\hline$R^{2}$ & $\mathrm{NC}$ & 0.83 & $\mathrm{NC}$ & $\mathrm{NC}$ & 0.98 & $\mathrm{NC}$ & 0.79 & $\mathrm{NC}$ \\
\hline \multicolumn{9}{|l|}{ Minn14 } \\
\hline $\mathrm{CO}$ & 17.2 & 4.6 & 2.7 & 15.9 & 0.91 & 0.90 & 0.45 & 19.9 \\
\hline $\mathrm{C} 1$ & 16.7 & 4.5 & 2.7 & 15.1 & 0.90 & 0.94 & 0.44 & 20.0 \\
\hline $\mathrm{C} 2$ & 16.5 & 4.4 & 2.7 & 14.6 & 0.88 & 0.95 & 0.47 & 21.1 \\
\hline C3 & 15.9 & 4.3 & 2.6 & 14.5 & 0.85 & 0.94 & 0.44 & 20.2 \\
\hline $\operatorname{LSD}_{(0.05)}$ & 0.7 & 0.1 & NS & 0.8 & NS & NS & 0.02 & NS \\
\hline Linear & $-0.40^{* *}$ & $-0.08^{* * *}$ & NS & $-0.48^{* *}$ & $-0.02^{*}$ & NS & NS & NS \\
\hline Quadratic & NS & NS & $\mathrm{NC}$ & NS & NS & $\mathrm{NC}$ & $\mathrm{NC}$ & $\mathrm{NC}$ \\
\hline$R^{2}$ & 0.98 & 0.96 & $\mathrm{NC}$ & 0.90 & 0.92 & $\mathrm{NC}$ & $\mathrm{NC}$ & $\mathrm{NC}$ \\
\hline \multicolumn{9}{|l|}{ NECDR } \\
\hline $\mathrm{CO}$ & 16.5 & 4.5 & 2.8 & 15.6 & 0.85 & 0.90 & 0.45 & 19.3 \\
\hline $\mathrm{C} 1$ & 15.6 & 4.5 & 2.7 & 16.1 & 0.90 & 0.89 & 0.45 & 19.9 \\
\hline $\mathrm{C} 2$ & 15.3 & 4.6 & 2.8 & 16.0 & 0.90 & 0.90 & 0.45 & 20.1 \\
\hline $\mathrm{C} 3$ & 14.7 & 4.5 & 2.7 & 15.4 & 0.88 & 0.91 & 0.46 & 20.4 \\
\hline LSD (0.05) & 0.8 & NS & NS & NS & NS & NS & NS & NS \\
\hline Linear & $-0.57^{* *}$ & NS & NS & NS & NS & NS & NS & NS \\
\hline Quadratic & NS & $\mathrm{NC}$ & $\mathrm{NC}$ & $\mathrm{NC}$ & $\mathrm{NC}$ & $\mathrm{NC}$ & $\mathrm{NC}$ & $\mathrm{NC}$ \\
\hline$R^{2}$ & 0.96 & $\mathrm{NC}$ & $\mathrm{NC}$ & $\mathrm{NC}$ & $\mathrm{NC}$ & $\mathrm{NC}$ & $\mathrm{NC}$ & $\mathrm{NC}$ \\
\hline
\end{tabular}

${ }^{\mathrm{z}} \mathrm{NC}=$ not calculated due to a nonsignificant linear response.

Ns,*,*** Nonsignificant or significant at $P<0.05$ or 0.01 probability levels, respectively. 
significant, entries were tested with the overall error from the combined analysis of variance. Least significant differences (LSDS) at $P<0.05$ were used to separate cycle means.

\section{Results and Discussion}

Significant year and planting date effects were found for most traits in each population (data not shown). Single degree of freedom contrasts testing rust infested vs. nonrust infested environments were significant for ear length in Minn 11; kernel thickness in NECDR; cob width, kernel depth, and 100 kernel weight in both of these populations; and all traits except cob width in Minn14 (data not shown). For traits with significant contrasts, means in nonrust infested environments were greater than rust infested environments. This may have been caused by differences in the level of rust infection, by planting date, or both variables. For traits that had significant environmental effects but nonsignificant contrasts, means did not follow any discernable pattern, indicating that environmental conditions in addition to the degree of rust infection affected these traits differentially.

Significant correlated linear responses to selection occurred in ear width, kernel depth, and kernel thickness in Minn11; in ear length, ear width, row number, and kernel depth in Minn14; and in ear length in NECDR with $R^{2}$ values ranging from 0.79 to 0.98 (Table 1$)$. A significant $(P<0.05)$ quadratic component also occurred for ear width and kernel depth in Minn11. Cycle $\times$ environment interaction occurred only for cob width in Minn14 (data not shown).

Ear length declined from $17.2 \mathrm{~cm}$ to $15.9 \mathrm{~cm}$ in Minn14 and from $16.5 \mathrm{~cm}$ to $14.7 \mathrm{~cm}$ in NECDR while ear width decreased from $4.4 \mathrm{~cm}$ to $4.2 \mathrm{~cm}$ in Minn11 and from $4.6 \mathrm{~cm}$ to $4.3 \mathrm{~cm}$ in Minn14, over cycles (Table 1). In Minn14, row number decreased from 15.9 rows/ear in cycle 0 to 14.5 rows/ear in cycle 3 . Kernel depth decreased from $0.86 \mathrm{~cm}$ to $0.80 \mathrm{~cm}$ in Minn11 and from $0.91 \mathrm{~cm}$ to $0.85 \mathrm{~cm}$ in Minn14, over cycles. In Minn11 and Minn14, but not in NECDR, changes in ear quality traits over cycles of selection were associated with decreasing ear weight (Abedon and Tracy, 1998).

Results herein indicate selection for resistance to common rust generally resulted in shorter ears in Minn14 and NECDR, and shallower kernels in Minn11 and Minn14. Both of these changes could result in reduced cut kernel yield for processors. The nonsignificant cycle $\times$ environment interaction for most traits indicates similar responses occurred in both rust infested and nonrust infested environments. Although recurrent selection for pest resistance can result in decreased agronomic performance in pest-free environments (Klenke et al., 1986), it was surprising that ear length and kernel depth in cycle 3 were lower than in cycle 0 even under rust epiphytotics. Because ear traits tended to be affected by selection differently in each population, random genetic drift may have been responsible, at least in part, for the observed changes. Inbreeding can also be a factor during a recurrent selection program. However, since inbreeding usually results in later flowering (Hallauer and Miranda, 1988) and each population flowered earlier over cycles (Abedon and Tracy, 1998), inbreeding was probably negligible in this study. In fact, earlier flowering, per se, may have contributed to these results since yield tends to be positively correlated with flowering time (Troyer, 1990). Correlated responses in ear quality traits may have also been due to decreased total leaf area in cycle 3 relative to cycle 0 of each population because selection also resulted in reduced leaf number, leaf length, and leaf width (Abedon, 1997; Abedon and Tracy, 1998). Our results indicate that selection for rust resistance resulted in significant, but minor, changes in ear quality. Changes in specific traits varied with population. Consequently, we recommend that selection for ear quality traits need not accompany selection for resistance to common rust if maintenance of ear quality is desired.

\section{Literature Cited}

Abedon, B.G. 1997. Timing of vegetative phase change in maize: Genetics and relationship with agronomic performance. PhD diss., Univ. of Wisconsin-Madison.

Abedon, B.G. and W.F. Tracy. 1998. Direct and indirect effects of recurrent selection for resistance to common rust (Puccinia sorghi Schw.) in three sweet corn populations. Crop Sci. 38:56-61.

Eberhart, S.A. 1964. Least squares method for comparing progress among recurrent selection methods. Crop Sci. 4:230-231.

Groth, J.V., R.J. Zeyen, D.W. Davis, and B.J. Christ. 1983. Yield and quality losses caused by common rust (Puccinia sorghi Schw.) in sweet corn (Zea mays) hybrids. Crop Prot. 2:105-111.

Hallauer, A.R. and J.B. Miranda, Fo. 1988. Quantitative genetics in maize breeding. Iowa State Univ. Press, Ames.

Hooker, A.L. 1969. Widely based resistance to rust in corn. Iowa Agr. Expt. Sta. Rpt. 64:28-34.

Kim, S.K. and J.L. Brewbaker. 1977. Inheritance of general resistance in maize to Puccinia sorghi Schw. Crop Sci. 17:456-461.

Klenke, J.R., W.A. Russell, and W.D. Guthrie. 1986. Recurrent selection for resistance to European corn borer in a corn synthetic and correlated effects on agronomic traits. Crop Sci. 26:864-868.

Pataky, J.K. and J.M. Headrick. 1989. Management of common rust on sweet corn with resistance and fungicides. J. Prod. Agr. 2:362-369.

Randle, W.M., D.W. Davis, and J.V. Groth. 1984a. Improvement and genetic control of partial resistance in sweet corn to corn leaf rust. J. Amer. Soc. Hort. Sci. 109:777-781.

Randle, W.M., D.W. Davis, and J.V. Groth. 1984b. The effects of corn leaf rust on maturity and quality of fresh market ears of sweet corn. J. Amer. Soc. Hort. Sci. 109:645-648.

Troyer, A.F. 1990. Selection for early flowering in corn: Three adapted synthetics. Crop Sci. 30:896-900. 